\title{
Modulation of intracellular calcium signaling by microRNA-34a-5p
}

\author{
Caroline Diener (1), Martin Hart ${ }^{1}$, Dalia Alansary², Vanessa Poth², Barbara Walch-Rückheim³ , Jennifer Menegatti ${ }^{4}$, \\ Friedrich Grässer ${ }^{4}$, Tobias Fehlmann ${ }^{5}$, Stefanie Rheinheimer ${ }^{1}$, Barbara A. Niemeyer $\mathbb{B}^{2}$, Hans-Peter Lenhof ${ }^{6}$, \\ Andreas Keller $\mathbb{1}^{5}$ and Eckart Meese ${ }^{1}$
}

\begin{abstract}
Adjusting intracellular calcium signaling is an important feature in the regulation of immune cell function and survival. Here we show that miR-34a-5p, a small non-coding RNA that is deregulated in many common diseases, is a regulator of store-operated $\mathrm{Ca}^{2+}$ entry (SOCE) and calcineurin signaling. Upon miR-34a-5p overexpression, we observed both a decreased depletion of ER calcium content and a decreased $\mathrm{Ca}^{2+}$ influx through $\mathrm{Ca}^{2+}$ release-activated $\mathrm{Ca}^{2+}$ channels. Based on an in silico target prediction we identified multiple miR-34a-5p target genes within both pathways that are implicated in the balance between T-cell activation and apoptosis including ITPR2, CAMLG, STIM1, ORAI3, RCAN1, PPP3R1, and NFATC4. Functional analysis revealed a decrease in $\mathrm{Ca}^{2+}$ activated calcineurin pathway activity measured by a reduced IL-2 secretion due to miR-34a-5p overexpression. Impacting SOCE and/or downstream calcineurin/NFAT signaling by miR-34a-5p offers a possible future approach to manipulate immune cells for clinical interventions.
\end{abstract}

\section{Introduction}

Store-operated $\mathrm{Ca}^{2+}$ entry (SOCE) is the central calcium signaling pathway in $\mathrm{T}$ cells, regulating cellular activation, proliferation, and migration ${ }^{1}$. Furthermore, apoptosis regulation by intracellular calcium signaling has an important role for negative selection of auto-reactive $\mathrm{T}$ cells and $\mathrm{T}$-cell proliferation control during adaptive immune response $\mathrm{e}^{2-4}$. Upon $\mathrm{T}$-cell receptor (TCR) activation, the second messenger $\mathrm{IP}_{3}$ (inositol 1,4,5-trisphosphate) binds to its receptor in the membrane of endoplasmic reticulum (ER) resulting in a depletion of ER $\mathrm{Ca}^{2+}$ stores $^{5-7}$. This in turn causes conformational changes and oligomerization of the ER $\mathrm{Ca}^{2+}$ sensor STIM (stromal interaction molecule), accompanied by translocation to the plasma membrane ${ }^{8-10}$. Interaction of STIM with $\mathrm{Ca}^{2+}$ pore-forming ORAI proteins subsequently

\footnotetext{
Correspondence: Caroline Diener (caroline.diener@uni-saarland.de) ${ }^{1}$ Institute of Human Genetics, Saarland University, 66421 Homburg, Germany ${ }^{2}$ Molecular Biophysics, Center for Integrative Physiology and Molecular Medicine, School of Medicine, Saarland University, 66421 Homburg, Germany Full list of author information is available at the end of the article. These authors contributed equally: Caroline Diener and Martin Hart Edited by H.-U. Simon
}

induces a concentration-dependent influx of $\mathrm{Ca}^{2+}$ ions from extracellular space ${ }^{11,12}$. Within the cell, $\mathrm{Ca}^{2+}$ is transported to refill intracellular stores and serves as second messenger ${ }^{13,14}$. Various $\mathrm{Ca}^{2}$ ${ }^{+}$-induced pathways, including the calcineurin/nuclear factor of activated T-cell (NFAT) pathway, finally result in transcriptional activation of genes that are essential for Tcell activity ${ }^{14,15}$. Based on its central role for $\mathrm{T}$-cell functions, a deregulation in SOCE is associated with immune deficiency and a reduced anti-tumor immunity in cancer $^{16-18}$.

A recent study on mouse CD4 $+\mathrm{T}$ cells possessing an aberrant microRNA biogenesis reveals changes in efficiency of SOCE, suggesting a functional role of miRNAs in SOCE regulation ${ }^{19}$. MicroRNAs (miRs) are small, noncoding RNAs that specifically bind to complementary sequences within the $3^{\prime}$-untranslated region (UTR) of their respective target mRNAs ${ }^{20,21}$. Due to a conjunction with miR-induced silencing complex, miR binding leads to an inhibition of translation or target mRNA degradation and results in a reduction of corresponding protein

\section{(c) The Author(s) 2018}

(c) (i) Open Access This article is licensed under a Creative Commons Attribution 4.0 International License, which permits use, sharing, adaptation, distribution and reproduction c. in any medium or format, as long as you give appropriate credit to the original author(s) and the source, provide a link to the Creative Commons license, and indicate if changes were made. The images or other third party material in this article are included in the article's Creative Commons license, unless indicated otherwise in a credit line to the material. If material is not included in the article's Creative Commons license and your intended use is not permitted by statutory regulation or exceeds the permitted use, you will need to obtain permission directly from the copyright holder. To view a copy of this license, visit http://creativecommons.org/licenses/by/4.0/. 
level $^{22}$. Deregulated microRNAs have a central role for severe diseases including cancer and immune disorders $^{23,24}$. MicroRNA-34a (hsa-miR-34a-5p, miR-34a5p) appears to have a crucial role in cell function and has been suggested as therapeutic agent in cancer treatment $^{25-27}$. However, a first clinical trial for tumor therapy by miR-34a-5p had to be aborted by reason of detrimental side effects on immune cells ${ }^{28}$. This highlights the general need for a better understanding of the regulatory impact of miR-34a-5p on immune cell function ${ }^{29}$. We recently found expressional changes of miR-34a-5p in $\mathrm{T}$ cells of lung cancer patients and miR-34a-5p-mediated targeting of the protein kinase c family, which is central to signaling through TCR and is also described to regulate apopto$\mathrm{sis}^{30-32}$. Beside the aforementioned general association of miRs in SOCE regulation and T-cell function, as of now the impact of miRs on SOCE pathway and the downstream calcineurin signaling remains to be further elucidated $^{33}$. Here we demonstrate that miR-34a-5p is a central regulator of store-operated $\mathrm{Ca}^{2+}$ signaling and downstream calcineurin/NFAT pathway.

\section{Results}

\section{MiR-34a-5p overexpression reduces SOCE in Jurkat cells}

To test the impact of miR-34a-5p on SOCE, we analyzed the functional effect of its overexpression on human T-cell line Jurkat. Cells were transfected either with miR34a-5p mimic or control mimic (AllStars Negative Control, ANC) RNA for $48 \mathrm{~h}$ before loading with Fura-2-AM. ER depletion was induced by sarco/endoplasmic reticulum $\mathrm{Ca}^{2+}$-ATPase (SERCA) pump inhibitor Thapsigargin $(\mathrm{Tg})$ and $\mathrm{Ca}^{2+}$ release-activated $\mathrm{Ca}^{2+}$ (CRAC) influx was initiated, providing external $\mathrm{Ca}^{2+}$ solution. As excitation maximum of Fura-2 fluorescent dye changes from $\lambda=$ $380 \mathrm{~nm}$ to $\lambda=340 \mathrm{~nm}$, when bound to cytosolic $\mathrm{Ca}^{2+}$, relative changes in intracellular calcium concentration were determined by Ratio (340/380) (Fig. 1a).

Statistical evaluation of the functional imaging sections (Fig. 1b) showed no significant effects of miR-34a-5p overexpression on ratio (340/380) in resting cells (basal ratio), as well as in CRAC influx rate and in the plateau phase of CRAC channel activity ( $\Delta$ ratio plateau). Overexpression of miR-34a-5p however led to a significantly reduced ratio (340/380) for ER depletion by $\mathrm{Tg}$, which was 78.31\% compared with control transfected cells. Similar situation was detected for influx peak through CRAC channels ( $\Delta$ ratio peak), which was reduced to $84.35 \%$ compared with control transfected cells.

\section{MiR-34a-5p targets SOCE and calcineurin/NFAT signaling- related genes}

In order to identify target genes of miR-34a-5p related to SOCE and downstream calcineurin signaling, we performed an in silico target prediction. Regulation by miR-

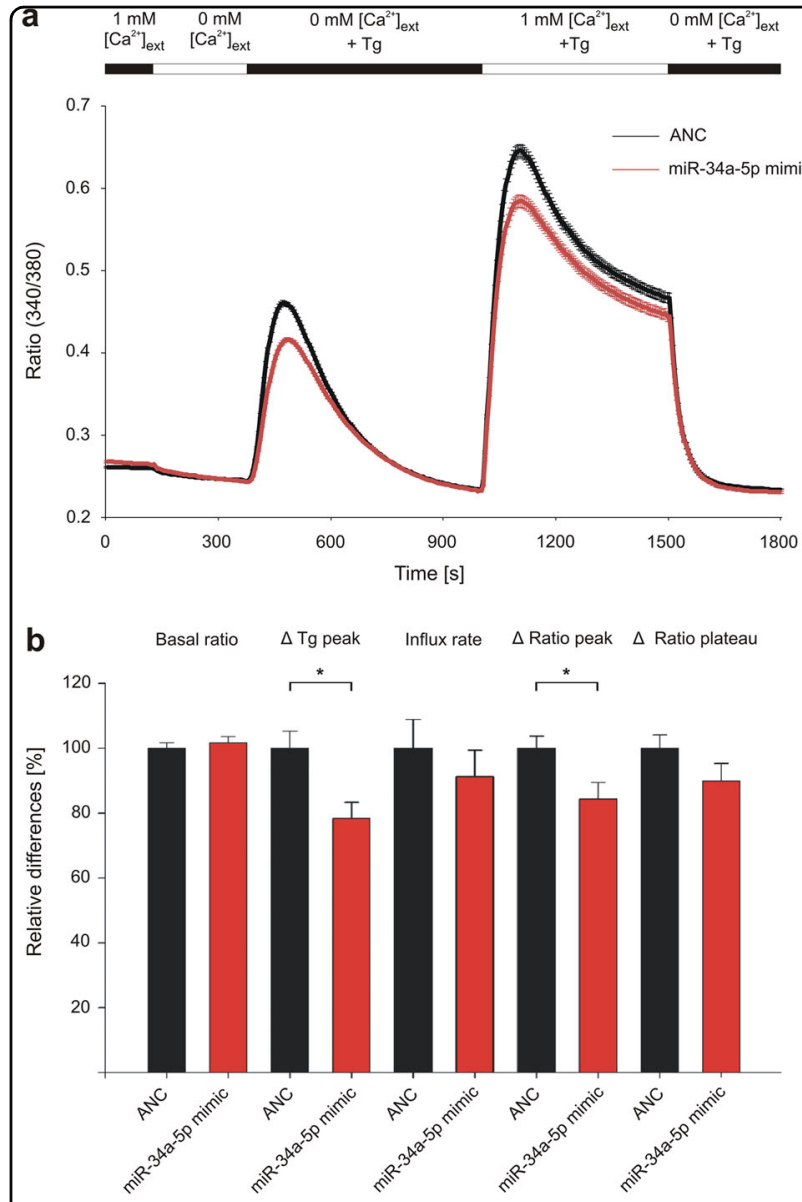

Fig. 1 Impact of miR-34a-5p overexpression on store-operated calcium entry in Jurkat cells. Jurkat cells were transfected for $48 \mathrm{~h}$ either with non-targeting control (ANC) or synthetic miR-34a-5p mimic. Respective $\mathrm{Ca}^{2+}$ imaging was performed in five independent experiments on 3 days of measurement. Intracellular $\mathrm{Ca}^{2+}$ was sensed by Fura-2-AM fluorescent dye and SOCE was induced by Thapsigargin ( $\mathrm{Tg})$. Cells were perfused with different solutions providing external $\mathrm{Ca}^{2+}\left(\left[\mathrm{Ca}^{2+}\right]_{\text {ext }}\right)$. a Quotient of Fura-2 fluorescence (Ratio (340/380)) was determined over time of measurement as mean of all tested cells (ANC: $n=710$; miR-34a-5p: $n=756$ ). b Ratio (340/380) and delta ratio (340/380) were determined for the functional sections of imaging procedure and evaluated as mean for each of the five experiments. Results were standardized to controls and are shown as means of all experiments with corresponding standard errors (SEM). Statistical evaluation was performed using Student's $t$-test. A normal distribution of the data was assumed. ( $\left.{ }^{*} p \leq 0.05\right)$

$34 a-5 p$ was analyzed by dual luciferase reporter gene assays. Respective $3^{\prime}$-UTR sequences containing the predicted miR-binding sites were cloned into pMIR-RNL-TK reporter plasmid. Activity of firefly luciferase was measured after $48 \mathrm{~h}$ co-transfection of HEK293T cells with microRNA-34a expression plasmids (pSG5-miR-34a) or control (pSG5). Binding of the miR to the $3^{\prime}$-UTR was detected by a decline in relative luciferase activity.

Out of 12 predicted and tested miR-34a-5p target genes, 7 were identified being determinably effected by miR-34a- 
5p. We observed no effect of miR-34a expression on ITPR1 and ITPR3 (inositol 1,4,5-trisphosphate receptor 1 and 3), CALM3 (Calmodulin 3), as well as ATP2A2 and ATP2A3 (ATPase sarcoplasmic/endoplasmic reticulum $\mathrm{Ca} 2+$ transporting 2 and 3) 3'-UTRs (Supplementary Figures 1 and 2). ITPR2 (inositol 1,4,5-trisphosphate receptor 2), CAMLG (calcium-modulating ligand), STIM1, and ORAI3 (ORAI calcium release-activated calcium modulator 3) were identified as direct target genes of miR-34a-5p with relation to SOCE (Fig. 2). Analysis of ITPR2-3'-UTR-containing construct in luciferase assays showed a decrease of relative luciferase activity to $76.32 \%$ in cells overexpressing miR-34a. Compared with empty reporter vector, this effect was statistically significant. The miR-34a-5p-specific effect was further confirmed by mutating the predicted binding sequence. The CAMLG3'-UTR construct showed a significantly reduced luciferase activity (73.37\%) upon miR-34a overexpression. Again, this effect was statistically significant as compared with empty reporter vector and further confirmed by mutating the predicted binding sequence. STIM1-3'-UTR constructs also showed a significant reduced luciferase activity (73.1\%), which was reconstituted by mutation of specific miR-34a-5p-binding site. ORAI3-3'-UTR construct also led to a significant decline in relative luciferase activity (74.93\%) upon miR-34a overexpression. The mutation of single binding sites respectively showed a significant reduction of reporter construct activity by miR-34a overexpression. The relative luciferase activity was reduced to $81.61 \%$ for the first binding site and to $73.29 \%$ for the second. By testing double mutated constructs, the luciferase activity was reconstituted, showing a combined function of both miR-34a-5p-binding sites.

RCAN1 (regulator of calcineurin 1), PPP3R1 (protein phosphatase 3 regulatory subunit $B$, alpha), as well as NFATC4 were further identified as miR-34a-5p target genes important for calcineurin/NFAT signaling (Fig. 3). In comparison with empty reporter plasmid, testing of RCAN1-3'-UTR reporter gene construct revealed a reduced activity of luciferase (54.94\%). The effect of miR$34 a-5 p$ binding again was verified by an increase in reporter gene activity of the mutated construct. Relative luciferase activity of wild-type PPP3R1-3'-UTR construct was reduced by miR-34a overexpression to a content of $63.07 \%$. Mutation of binding site one or two respectively within the PPP3R1 reporter gene construct also led to a significantly reduced luciferase activity to 87.13 and $76.43 \%$, compared with empty control plasmid. Testing of the double mutated construct resulted in a reconstituted activity with significant differences to wild-type $3^{\prime}$-UTR plasmid and verified a functional impact of both binding sites. Analysis of NFATC4 resulted in similar findings. The effects of miR-34a overexpression on NFATC4-3'UTR constructs led to a reduced relative luciferase activity to $51.96 \%$ for wild type, and $73.52 \%$ and $70.52 \%$ for the respective single mutated constructs. Mutation of both miR-34a-5p-binding sites reconstituted the luciferase activity.

\section{MiR-34a-5p overexpression reduces endogenous STIM1, PPP3R1, and NFATC4 protein levels}

Due to the central roles of STIM, calcineurin, and NFAT in SOCE and calcineurin pathway, respectively, we analyzed endogenous protein level of STIM1, PPP3R1, and NFATC4 upon microRNA-34a overexpression. The abundance of endogenous NFATC4 and STIM1 mRNA, as well as transfection efficiency of miR-34a-5p in Jurkat cells were shown by quantitative reverse-transcriptase PCR (RT-PCR) (Supplementary Figure 3). Endogenous protein expression of NFATC4, STIM1, and PPP3R1 was analyzed by western blotting in Jurkat cells (Supplementary Figure 4). Cells were transfected using miR-34a-5p mimic or control mimic (ANC) RNA for $48 \mathrm{~h}$. Proteins were separated by SDS-polyacrylamide gel electrophoresis (PAGE) and the target proteins were identified by specific monoclonal antibodies. Relative protein expression was related to a $\beta$-Actin loading control. In Jurkat lymphocytes overexpressing miR-34a-5p, NFATC4 protein level was significantly reduced to $80.39 \%$ as a result of five independent experiments. Relative endogenous STIM1 expression was reduced upon miR-34a-5p overexpression to $71.79 \%$ and PPP3R1 protein level was reduced to 64.40\% (Fig. 4).

\section{MiR-34a-5p overexpression reduces IL-2 production in Jurkat cells}

Toward a functional analysis of miR-34a-5p overexpression in calcium induced $\mathrm{T}$-cell activation, we analyzed calcium-calcineurin signaling regulated production of cytokine interleukin-2 (IL-2) in Jurkat cell line E6.1. To this end, Jurkat E6.1 cells were activated by $\alpha \mathrm{CD} 2 / \alpha \mathrm{CD} 3 /$ $\alpha \mathrm{CD} 28$ beads and phorbol 12-myristate 13-acetate (PMA) subsequent to transfection with ANC or miR-34a-5p mimic. The total number of the activated, IL-2-producing cells was determined and IL-2 quantification in the supernatants was performed by enzyme-linked immunosorbent assay (ELISA) $24 \mathrm{~h}$ after activation in five independent experiments (Fig. 5). MiR-34a-5p overexpression reduced IL-2 production to $74.78 \%$ as compared with control transfected cells. The mean count of miR-34a-5ptransfected cells was slightly but not significantly increased $\left(7.74 \times 10^{5}\right.$ cells $)$ as compared with control 


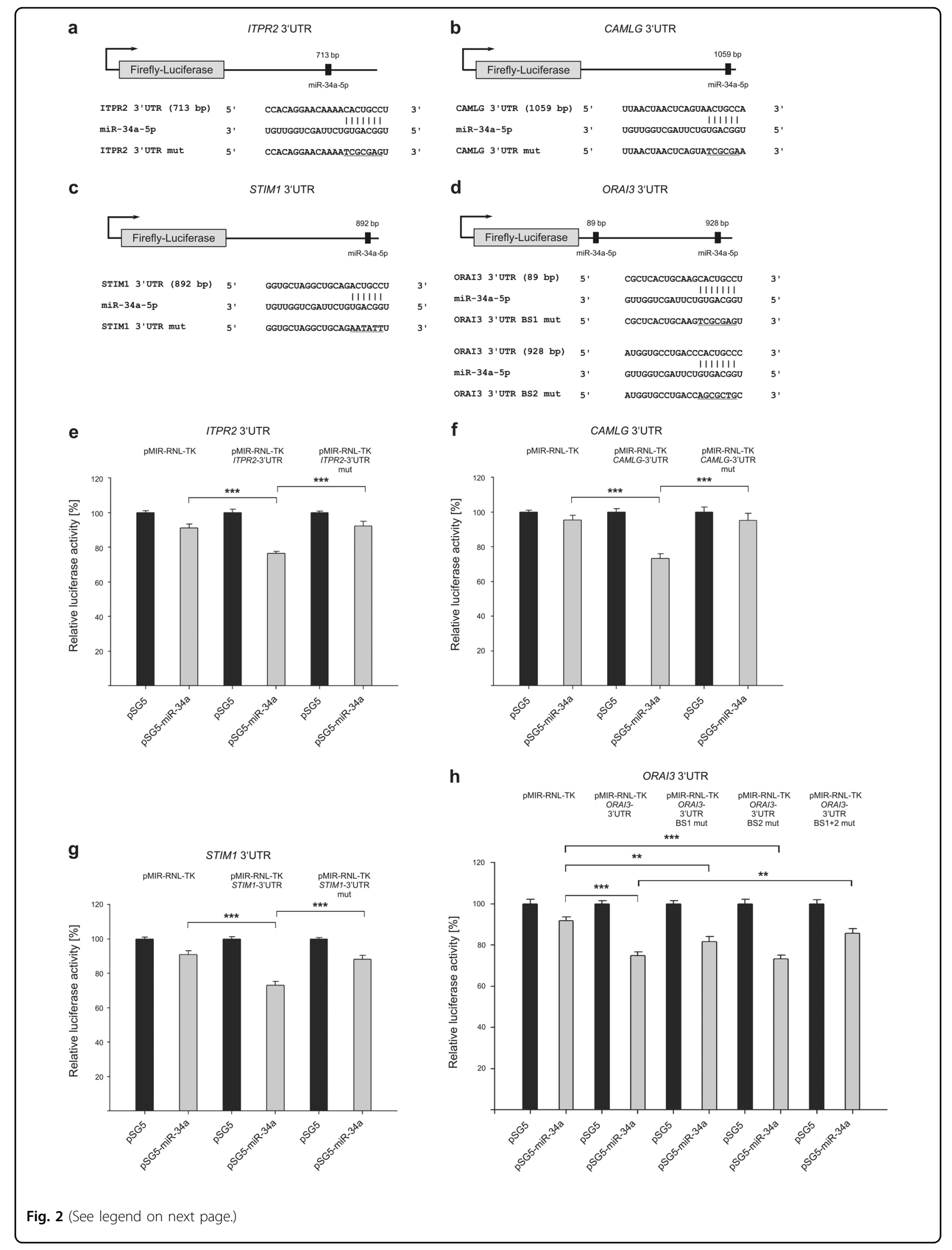


(see figure on previous page)

Fig. 2 Schematic representation of reporter gene constructs and results of luciferase assays, showing the impact of miR-34a-5p on target genes related to store-operated $\mathbf{C a}^{2+}$ entry. a-d 3'-UTR sequences of ITPR2 (inositol 1,4,5-trisphosphate receptor type 2), CAMLG (calciummodulating ligand), STIM1 (stromal interaction molecule 1), and ORAI3 (ORAI calcium release-activated calcium modulator 3) were cloned into pMIRRNL-TK reporter plasmids. The positions of the predicted miR-34a-5p-binding sites within the cloned $3^{\prime}-U T R$ reporter constructs are illustrated and denoted. Mutated binding sites are shown underlined. $\mathbf{e}-\mathbf{h}$ Relative luciferase activity [\%] is shown for empty reporter plasmids (pMIR-RNL-TK), as well as wild type and mutated (mut) 3'-UTR-containing constructs. HEK293T cells were co-transfected with control (pSG5) or miR-34a expression plasmids. Luciferase activities were measured $48 \mathrm{~h}$ after transfection. Results are shown as means of four independent experiments with

corresponding standard errors (SEM). Statistical evaluation was performed using Student's t-test. A normal distribution of the data was assumed. $\left({ }^{*} p \leq 0.05,{ }^{* *} p<0.01,{ }^{* * *} p<0.001\right.$; statistical comparison between wild-type $3^{\prime}$-UTR and mutated $3^{\prime}$-UTR containing two miR-34a-5p-binding sites was only performed for double mutated constructs)

transfected cells $\left(6.98 \times 10^{5}\right.$ cells). The same was true for the counts of non-activated Jurkat cells 48,72 , or $96 \mathrm{~h}$ post transfection (Supplementary Figure 5).

\section{MiR-34a-5p overexpression reduces calcium influx in T-cell activation signaling of Jurkat cells}

To further confirm the effect of miR-34a-5p overexpression on calcium signaling, calcium imaging was performed for Jurkat cells upon stimulation by $\alpha \mathrm{CD} 2 /$ $\alpha C D 3 / \alpha C D 28$ beads (Fig. 6). Relative changes in intracellular calcium concentration were determined by ratio (340/380) of Fura-2-AM fluorescent dye and absolute calcium concentrations were determined by calibration of Fura-2 Ratio within wild-type cells. No significant effects of miR-34a-5p overexpression were observed on basal calcium or within the plateau phase of SOCE $(\Delta$ calcium plateau). Overexpression of miR-34a-5p, however, led to a significantly reduced $\mathrm{Ca}^{2+}$ influx rate induced by bead contact $\left(8.61 \mathrm{nM} \mathrm{Ca}^{2+} / \mathrm{s}\right)$. In comparison, influx rate of cells transfected by negative control RNA was $10.23 \mathrm{nM}$ $\mathrm{Ca}^{2+} / \mathrm{s}$. Overexpression of miR-34a-5p led to a reduced intracellular calcium peak after the influx phase as well. In detail, the $\Delta$ calcium peak of cells transfected by miR-34a$5 \mathrm{p}$ mimic was significantly reduced $(655.45 \mathrm{nM})$ as compared with control cells showing a $\Delta$ peak of $803.11 \mathrm{nM}$.

\section{Discussion}

MiR-34a-5p is involved in regulation of cell cycle, migration, differentiation, and apoptosis ${ }^{25}$. We recently showed that miR-34a targets several members of the protein kinase $\mathrm{C}$ family, which functions in $\mathrm{Ca}^{2+}$ signaling through TCR. We also found significantly elevated miR$34 a-5 p$ expression in $\mathrm{CD} 3+\mathrm{T}$ cells of lung cancer patients $^{30,31}$. Here we show that miR-34a-5p is a key regulator of SOCE and calcineurin signaling. In the following, we address the miR-34a-5p targets and the effects of a downregulation of these targets.

The most upstream miR-34a-5p target gene we identified of SOCE pathway was ITPR2. ITPR2 is encoding for IP3 receptor (IP3R) type 2, which is located in the ER membrane ${ }^{34,35}$. Among the three types of $\mathrm{IP}_{3}$ Rs that are expressed in T cells (ITPR1, ITPR2, and ITPR3), type 2 shows the highest sensitivity to $\mathrm{IP}_{3}{ }^{34-36}$. It is conceivable that the activation of IP3Rs via TCR first leads to a depletion of ER $\mathrm{Ca}^{2+}$ stores and the induction of $\mathrm{SOCE}^{5-}$ 7 , followed by a period of reduced responsiveness mediated by miR-34a-5p that downregulates ITPR2.

The second gene, which we identified as a target gene of miR-34a-5p encoding an ER membrane protein, was CAMLG. Overexpression of CAMLG in Jurkat cells causes $\mathrm{IP}_{3}$-independent influx of extracellular $\mathrm{Ca}^{2+}$ and enables NFAT-controlled transcription events ${ }^{37,38}$. CAMLG-depleted CD8 + positive T cells show a reduced ability of target cell destruction ${ }^{39}$. A miR-34a-5pdependent reduction of CAMLG protein level may therefore be associated with a reduced cytosolic $\mathrm{Ca}^{2+}$ concentration and a decrease in NFAT-mediated transcription to regulate $\mathrm{T}$-cell function.

ER $\mathrm{Ca}^{2+}$ depletion leads to activation of CRAC channels ${ }^{10}$. The CRAC consist of the $\mathrm{Ca}^{2+}$ sensor STIM, encoded by two different homologs in mammals (STIM1 and STIM2), and the pore-forming ORAI in plasma membrane, with three different mammalian homologs (ORAI1, ORAI2, and ORAI3) ${ }^{10,40-42}$. The ER $\mathrm{Ca}^{2+}$ sensor STIM1 is the third ER membrane protein that we identified as a target of miR-34a-5p. In conjunction with ORAI1, STIM1 is the primary component of the CRAC and enables proper SOCE function ${ }^{18,41}$. Deletion of STIM1 in mouse T cells is associated with a reduction in NFAT-regulated transcription and cytokine expression ${ }^{43}$. STIM1 mutations with a loss of STIM1 function result in the absence of SOCE and severe immune deficiency in human $^{17,18}$. In addition, we identified ORAI3 as a direct target gene of miR-34a-5p. ORAI3 forms homomeric or heteromeric channels in the plasma membrane ${ }^{44}$. Involvement of ORAI3 in channel formation leads to a reduced $\mathrm{Ca}^{2+}$ entry, when compared with homomeric ORAI1 channels $^{44,45}$. An increased ORAI3 expression within an inflammatory environment has been associated with a reduced sensitivity of effector $\mathrm{T}$ cells to reactive oxygen 


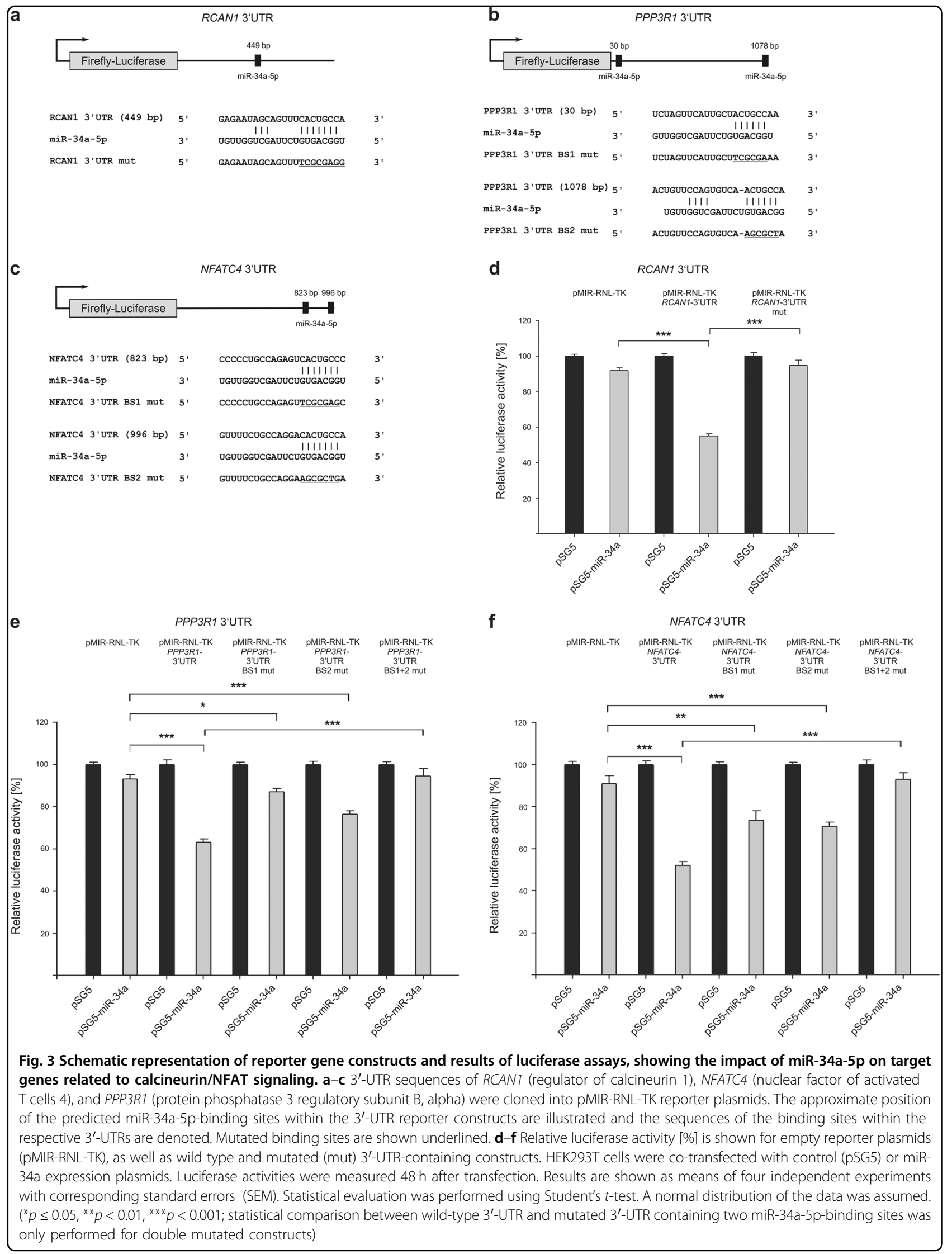




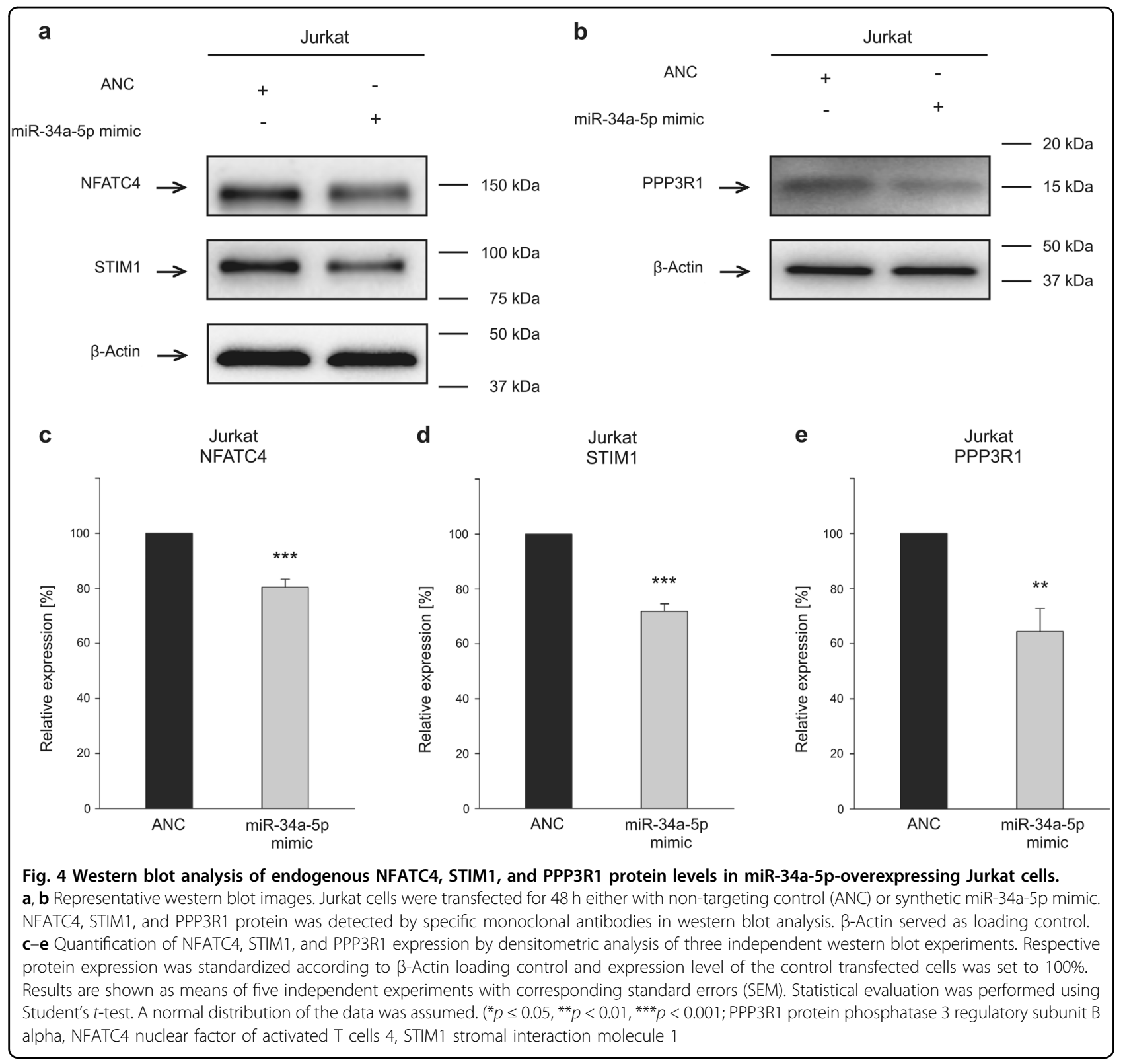

species $^{46}$. Based on these data, the posttranscriptional reduction of ORAI3 by miR-34a-5p is likely to be associated with an increased ROS sensitivity of effector T cells.

Analyzing the impact of miR-34a-5p overexpression on SOCE functionality by Tg-induced $\mathrm{Ca}^{2+}$ signaling revealed both a decreased ER depletion and a decreased maximum $\mathrm{Ca}^{2+}$ influx through CRAC channels. The same was true for a more physiological stimulation of calcium signaling by $\alpha C D 2 / \alpha C D 3 / \alpha C D 28$ beads. This led to a decreased calcium influx rate composed of the initial ER depletion and subsequent CRAC channel activation. In addition, the overexpression of miR-34a-5p reduced the maximum of $\mathrm{Ca}^{2+}$ influx. Besides IP3Rs, which are known to be responsible for ER calcium leak and ER depletion $^{47}$, CAMLG is likely to act on ER depletion as a potential ER leak channel or a SERCA inhibitor ${ }^{37}$. Hence, the reduced ER depletion may be due to the downregulation of ITPR2 and CAMLG in miR-34a-5poverexpressing cells. The reduced calcium entry of extracellular calcium in SOCE may result from STIM1 reduction in miR-34a-5p-overexpressing cells. Analysis of Jurkat cells with a reduced STIM1 expression by small interfering RNA also showed a decreased calcium influx through store-operated channels ${ }^{48}$. As ORAI3 involvement in $\mathrm{Ca}^{2+}$ channel formation leads to a reduced $\mathrm{Ca}^{2+}$ entry $^{44,45}$, a reduced ORAI3 expression in miR-34a-5poverexpressing cells should, however, result in an increase in SOCE. ORAI3 regulation by miR-34a-5p may impact 

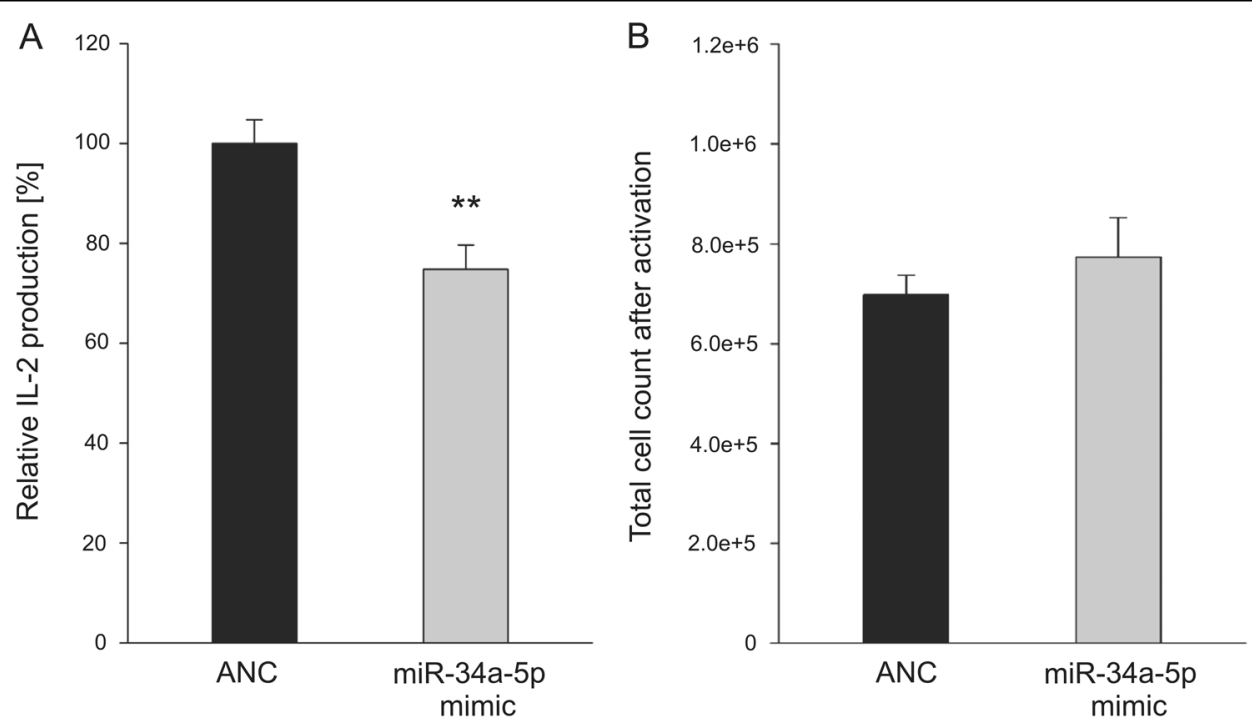

Fig. 5 IL-2 expression of miR-34a-5p-overexpressing cells. Jurkat E6.1 cells were transfected for $48 \mathrm{~h}$ either with non-targeting control (ANC) or synthetic miR-34a-5p mimic. Twenty-four hours post transfection, a count of $3.5 \times 10^{5}$ cells was activated for IL-2 production by CD2/CD3/CD28 beads and PMA. a IL-2 production was quantified by ELISA of the respective supernatants for a total of five independent experiments. Results of IL-2 production were standardized according the control transfected cells. b Corresponding cell counts were determined, when supernatants were collected. Results are shown as means with corresponding standard errors (SEM). Statistical evaluation was performed using Student's $t$-test. A normal distribution of the data was assumed. $\left({ }^{*} p \leq 0.05\right)$

SOCE to a lower degree than the miR-34a-5p-mediated STIM1 reduction, which regulates activity of all ORAI homologs. Nevertheless, the opposite effect of ORAI3 downregulation may partially diminish the effect caused by a reduced STIM1 expression upon miR-34a-5p overexpression.

Cytosolic $\mathrm{Ca}^{2+}$ serves as second messenger that induces pathways such as calcineurin/NFAT signaling ${ }^{14,15}$. Within the calcineurin/NFAT pathway, we and others identified RCAN1 as a miR-34a-5p target gene ${ }^{49}$. Depending on the RCAN phosphorylation status ${ }^{50}$, a reduced level of RCAN1 protein as a result of miR-34a-5p binding may lead to either an inhibition or an enhancement of calcineurin/NFAT signaling.

The second identified miR-34a-5p target gene of calcineurin/NFAT pathway was PPP3R1, which encodes calcineurin subunit $B$. Heteromeric calcineurin consists of a catalytic calcineurin A subunit and a regulatory B subunit ${ }^{51}$. Calcineurin $\mathrm{B}$ binds to intracellular $\mathrm{Ca}^{2+}$ and induces structural changes of calcineurin $\mathrm{A}^{52,53}$. Activation of calcineurin A subunit by cytosolic calcium sensor calmodulin subsequently facilitates dephosphorylation of transcription factor NFAT, resulting in nuclear NFAT translocation and enhanced transcription of T-cellactivating genes ${ }^{53-56}$. Moreover, calcineurin $\mathrm{B}$ prevents degradation of calcineurin $A^{57}$. Posttranscriptional downregulation of PPP3R1 gene by miR-34a-5p may therefore impact phosphatase activity as well as stability of the calcineurin complex. The third miR-34a-5p target gene within the calcineurin/NFAT pathway, we identified by luciferase assays and western blotting, was NFATC4 (NFATC4/ NFAT3). NFAT proteins constitute a family of transcription factors that enhance transcription of genes, which are crucial for T-cell activity ${ }^{55,56,58}$. Although there were some reports suggesting that NFATC4 is not expressed in T lymphocytes $^{59-61}$, we and others showed NFATC4 expression in $\mathrm{T}$ lymphocytes ${ }^{62,63}$. Downregulation of NFATC4 has been shown to be associated with effective cytokine expression in human $\mathrm{CD} 4+\mathrm{T}$ cells ${ }^{63}$, suggesting that regulation of NFATC4 expression by miR-34a-5p may take part in orchestrating this process.

We found that miR-34a-5p overexpression reduced IL-2 production. IL-2, which is known to be regulated by SOCE and NFAT/calcineurin signaling, is secreted during immune response and stimulates activation, proliferation, and effector functions in an auto- and paracrine manner ${ }^{64-66}$. The reduced secretion of IL-2 upon miR-34a-5p overexpression is likely to be mediated by the downregulation of the miR-34a-5p target genes verified within SOCE and calcineurin pathway. There may also be an impact on IL-2 transcription due to further miR-34a-5p targets and additional signaling cascades ${ }^{67}$.

T-cell apoptosis is regulated by calcium signaling and has an important role for the negative selection of autoreactive $T$ cells and the control of proliferating $T$ cells during adaptive immune response ${ }^{2-4}$. Besides the aforementioned effects on $\mathrm{T}$-cell activation, calcium regulation by miR-34a-5p may impact cellular viability ${ }^{68,69}$. 
$0.5 \mathrm{mM}\left[\mathrm{Ca}^{2+}\right]_{\text {ext }}$

a
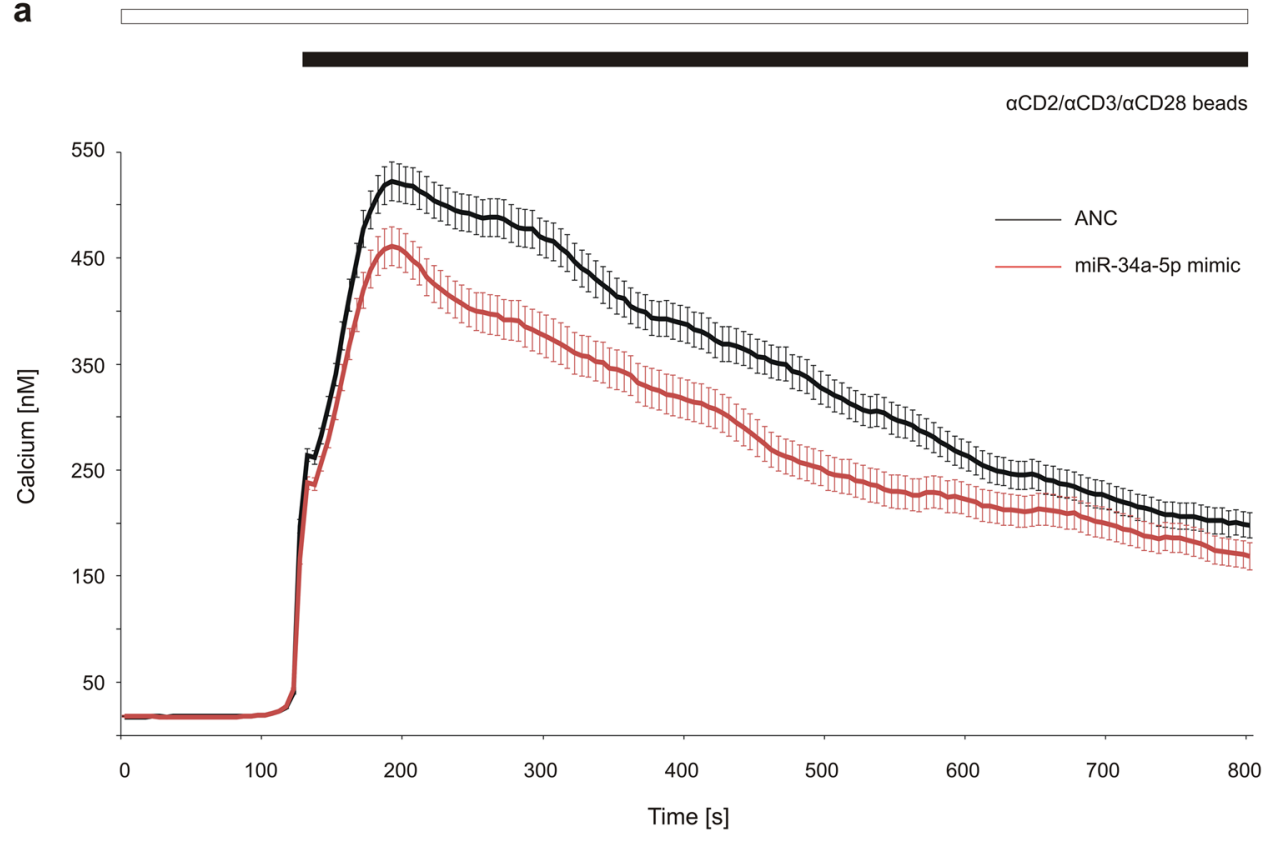

b

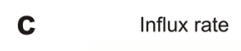

d

$\triangle$ Calcium peak

e $\Delta$ Calcium plateau
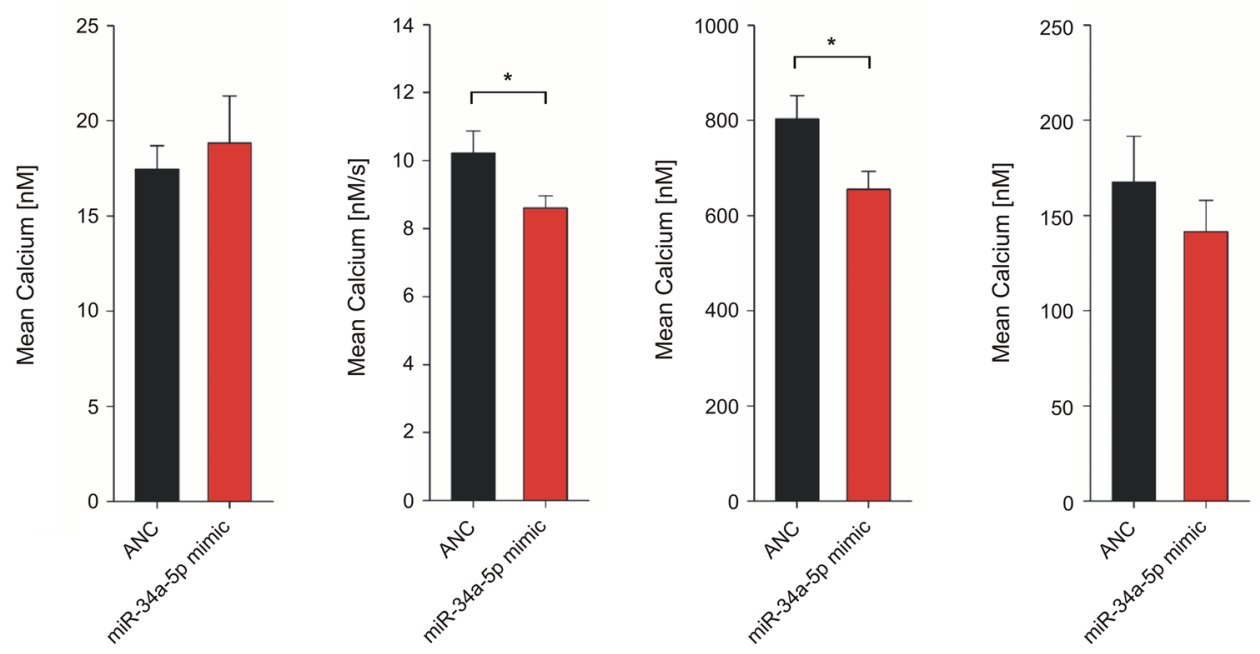

Fig. 6 Impact of miR-34a-5p overexpression on calcium signaling in Jurkat cell activation. Jurkat cells were transfected for $48 \mathrm{~h}$ either with non-targeting control (ANC) or synthetic miR-34a-5p mimic. Respective $\mathrm{Ca}^{2+}$ imaging was performed in eight independent experiments on 3 days of measurement. Intracellular $\mathrm{Ca}^{2+}$ was sensed by Fura-2-AM fluorescent dye and SOCE was induced by aCD2/aCD3/aCD28 beads, while providing external $\mathrm{Ca}^{2+}$ solution. a Intracellular calcium concentration was determined over time of measurement and is shown as mean of all tested cells (ANC: $n=407$; miR-34a-5p: $n=277$ ). $\mathbf{b}$-e Functional sections of the imaging procedure were evaluated as mean for each of the eight experiments respectively and are shown as mean for all experiments with corresponding SEM. Statistical evaluation was performed using Student's $t$-test. A normal distribution of the data was assumed. $\left({ }^{*} p \leq 0.05\right)$

Depletion of ER $\mathrm{Ca}^{2+}$ and its uptake into mitochondria are connected to intrinsic apoptosis pathway ${ }^{68,70}$. Extrinsic apoptosis signaling is initiated by secretion of fas ligand binding to fas receptors in a para- or an autocrine manner ${ }^{2,71,72}$. Expression of fas ligand is promoted by a depletion of ER calcium and is transcriptionally controlled by calcineurin/NFAT pathway ${ }^{73,74}$. Targeting of ITPR2 and STIM1, as well as calcineurin coding PPP3R1 and NFATC4 by miR-34a-5p may therefore exert an antiapoptotic effect through a reduced ER depletion and the downregulation of FAS/FASLG signaling. By contrast, a reduced protein level of CAMLG due to miR-34a-5p expression may lead to pro-apoptotic effects, as CAMLG has been shown to prevent cell death in activated 
$\mathrm{T}$ cells ${ }^{39}$. Hence, the complex regulatory feedback loop of miR-34a expression, immune cell activation, and apoptosis $^{75,76}$ may be influenced by a balance of pro- or antiapoptotic target genes of calcium signaling cascade, which in turn effects the cellular viability during adaptive immune response.

Taken together, miR-34a-5p overexpression leads to an inhibition of store-operated $\mathrm{Ca}^{2+}$ signaling and impacts downstream calcineurin/NFAT signaling by targeting specific related genes. Analyzing Jurkat cells as a model for T-cell activation, we observed reduction of SOCE and IL-2 secretion by miR-34a-5p overexpression. An increased miR-34a-5p expression may therefore negatively impact activation, proliferation, effector functions, as well as survival of $\mathrm{T}$ cells. These data and the previously observed overexpression of miR-34a-5p in T lymphocytes of cancer patients ${ }^{30,31}$ are possibly indicating an inhibition of immune cell function by miR-34a-5p in the anti-tumor immune response. Our results underline the need for a deeper understanding of the effects of miR-34a-5p overexpression on T-cell activation signaling. Further analyses will help to reveal the impact of miR-34a-5p overexpression on primary human $\mathrm{T}$ cells including different T- cell subtypes.

\section{Materials and methods \\ Cell lines}

Human Jurkat and HEK293T cell lines were purchased from the Leibniz Institute DSMZ-German collection of microorganisms and cell cultures. IL-2-producing Jurkat cell line E6.1 was purchased from European Collection of Authenticated Cell Cultures (Salisbury, UK). HEK293T cells were cultured in Dulbecco's modified Eagle's medium (Life Technologies GmbH, Darmstadt, Germany) and both Jurkat subtypes were cultured in RPMI 1640 medium (Life Technologies $\mathrm{GmbH}$ ), respectively, supplemented with $10 \%$ fetal bovine serum (Biochrom GmbH, Berlin, Germany), penicillin (100 U/mL), and streptomycin $(100 \mu \mathrm{g} / \mathrm{mL})$. Cells were passaged for less than 3 months after receipt.

\section{Tg-induced $\mathrm{Ca}^{2+}$ imaging analysis of miR-34a-5p- overexpressing Jurkat cells}

Jurkat cells/well $\left(2.5 \times 10^{5}\right)$ were seeded out in six-well plates and were transfected either with ANC or with synhsa-miR-34a-5p miScript miRNA Mimics (QIAGEN N. V., MIMAT0000255: 5'-UGGCAGUGUCUUAGCUGG UUGU-3'), complying with HiPerFect ${ }^{\mathrm{mi}}$ transfection reagent protocol (Qiagen, Hilden, Germany). Transfected cells were incubated for overall $48 \mathrm{~h}$ before $\mathrm{Ca}^{2+}$ imaging. Cells were loaded with $1 \mu \mathrm{M}$ Fura-2-AM (Invitrogen, Waltham, MA, USA) for $25 \mathrm{~min}$ at room temperature and fixed on poly-ornithine-coated glass coverslips. For imaging procedure, cells were perfused with different solutions, providing external $\mathrm{Ca}^{2+}$. External $\mathrm{Ca}^{2+}$ solution $(1 \mathrm{mM})$ contained $155 \mathrm{mM} \mathrm{NaCl}, 2 \mathrm{mM} \mathrm{MgCl} 2,10 \mathrm{mM}$ glucose, $5 \mathrm{mM}$ Hepes, and $1 \mathrm{mM} \mathrm{CaCl}$. In $0 \mathrm{mM} \mathrm{Ca}{ }^{2+}$ solution, $\mathrm{CaCl}_{2}$ was replaced by $1 \mathrm{mM}$ EGTA and $3 \mathrm{mM}$ $\mathrm{MgCl}_{2}$ (pH 7.4 with $\mathrm{NaOH}$ ). SOCE was induced using 1 $\mu \mathrm{M}$ irreversible SERCA inhibitor Tg (Invitrogen). Fura-2 fluorescence $(\mathrm{F})$ was detected alternating its excitation from $\lambda=340 \mathrm{~nm}\left(\mathrm{Ca}^{2+}\right.$ bound, $\left.\mathrm{F}_{340}\right)$ to $380 \mathrm{~nm}\left(\mathrm{Ca}^{2+}\right.$ free, $\mathrm{F}_{380}$ ). Images were analysed by TILLVision software (TILL Photonics GmbH, Gräfelfing, Germany). Ratio $(340 / 380)$ was determined by quotient $F_{340} / F_{380}$. Jurkat cells with basal calcium of $>0.4$ ratio $(340 / 380)$ were excluded from analysis as pre-activated. Ratio (340/380) was determined for the functional sections of imaging procedure using IGOR Pro (WaveMetrics) software. For delta ratio, the minimum before adding the $\mathrm{Tg}$ was subtracted from $\mathrm{Tg}$ peak ( $\Delta \mathrm{Tg}$ peak), ratio (340/380) before adding $1 \mathrm{mM} \mathrm{Ca}^{2+}$ solution was subtracted from ratio $(340 / 380)$ maximum and plateau, respectively ( $\Delta$ ratio peak, $\Delta$ ratio plateau). Influx rate was determined by the slope of ratio, when adding the $1 \mathrm{mM} \mathrm{Ca}{ }^{2+}$ solution.

\section{$\mathrm{Ca}^{2+}$ imaging analysis of activated Jurkat cells overexpressing miR-34a-5p}

Jurkat E6.1 cells were transfected with ANC or miR$34 a-5 p$ mimics for a period of $48 \mathrm{~h}$ and utilized for calcium imaging as described above. Calcium signaling was stimulated by MACSiBead ${ }^{\mathrm{m}}$ particles from human T Cell Activation/Expansion Kit (Miltenyi Biotec GmbH, Bergisch Gladbach, Germany). External calcium was provided by a $0.5 \mathrm{mM} \mathrm{Ca}^{2+}$ solution. Absolute intracellular $\mathrm{Ca}^{2+}$ concentration was determined by the in situ calibration of Fura-2-AM and calculated from $\left[\mathrm{Ca}^{2+}\right]_{\text {intracellular }}=\mathrm{K}^{*}$ $\left(\right.$ Ratio - Ratio $\left._{\text {min }}\right) /\left(\text { Ratio }_{\text {max }}-\text { Ratio }\right)^{77}$. At least 20 cells per measurement were chosen for calcium analysis by the criteria of a bead contact. The functional data were again analyzed with the software IGOR Pro (WaveMetrics). For calculation of delta calcium, basal calcium was subtracted from calcium peak ( $\Delta$ calcium peak) or from calcium plateau ( $\Delta$ calcium plateau), respectively.

\section{Target prediction and assembly of $3^{\prime}$-UTR reporter gene constructs}

We used miRWalk 2.0 (http://zmf.umm.uni-heidelberg.de/ apps/zmf/mirwalk2/index.html) for an in silico prediction of miR-34a-5p-binding sites within the $3^{\prime}$-UTR of possible target genes ${ }^{78}$. For that purpose, all through miRWalk 2.0 available databases were independently selected to find putative $3^{\prime}$-UTR target sides for seed binding, with a minimum of a $6 \mathrm{nt}$ seed sequence. Results were filtered for a prediction by more than four databases. Subsequently, we chose predicted target genes related to SOCE or calcineurin/ NFAT signaling. The respective 3 '-UTR sequences of predicted miR-34a-5p target genes were amplified by PCR using 
specific primer pairs (Supplementary Table 1) and cloned into the multiple cloning site of pMIR-RNL-TK plasmid $^{79}$, using SpeI and SacI restriction sites. Jurkat cDNA was used for template. The denoted parts of human GRCh38/hg38 genome have been cloned utilizing the declared NCBI sequences for reference: ATP2A2 3'-UTR (chr12:110,347,119-110,348,110; NM_170665.3), ATP2A3 3'-UTR (chr17:3,923,898-3,924,783; NM_005173.3), CALM3 3'-UTR (chr19:46,609,301-46,610,572; NM_005184.3), CAMLG 3'-UTR (chr5:134,750,951-134,752,087; NM_001745.3), ITPR1 3'-UTR (chr3:4,846,620-4,847,798; NM_001168272.1), ITPR2 3'-UTR (chr12:26,337,69026,338,767; NM_002223.3), ITPR3 3'-UTR (chr6:33,695,799_ 33,696,154; NM_002224.3), NFATC4 3'-UTR (chr14: 24,378,485-24,379,520; NM_001136022.2), ORAI3 3'-UTR (chr16:30,953,784-30,954,826; NM_152288.2), PPP3R1 3'UTR (chr2:68,179,165-68,180,278; NM_000945.3), RCAN1 3'-UTR (chr21:34,516,824-34,517,736; NM_004414.6), STIM1 3'-UTR (chr11:4,092,219-4,093,198; NM_ 001277961.1). MiR-34a-5p-binding sites were mutated by technique of overlap extension PCR using specific primers ${ }^{80}$ (Supplementary Table 2).

\section{Dual luciferase reporter gene assays}

HEK293T cells were seeded out to a count of $6.5 \times 10^{4}$ cells/well of a 24-well plate. The day after seeding, cells were transfected with $0.8 \mu \mathrm{g}$ pSG5 or pSG5-miR-34a expression plasmid, respectively, and either $0.2 \mu \mathrm{g} 3^{\prime}$-UTR reporter construct or empty pMIR-RNL-TK plasmid. Transfection was performed following the instructions of Polyfect $^{\mathrm{tm}}$ reagent protocol (Qiagen). Forty-eight hours after transfection, cells were lysed and extracts were measured referring to the protocol of Dual Luciferase ${ }^{\circledast}$ Reporter Assay System (Promega, Mannheim, Germany)

\section{RNA isolation and quantitative real-time PCR}

For analysis of gene expression in Jurkat cells, mRNA levels of ITPR1, ITPR2, ITPR3, ORAI1, ORAI2, ORAI3, STIM1, STIM2, NFATC4, and miR-34a-5p were quantified by RT-PCR. Untreated Jurkat cells were lysed using Qiazol (Qiagen) and total RNA was isolated by miRNeasy Mini KIT (Qiagen), following the manufacturer's protocol. Total RNA (150 ng) was reverse transcribed by miScript RT II Kit into cDNA. cDNA for subsequent miR quantification was transcribed using miScript HiSpec Buffer (Qiagen), for later mRNA quantification miScript HiFlex Buffer (Qiagen) was used. RNU48 and GAPDH served as endogenous control. Expression levels were analysed by miScript PCR System (Qiagen) and a StepOnePlus Real-Time PCR System (Applied Biosystems, Foster City, USA) following the manufacturer's instructions. Specific primer pairs (QuantiTect Primer Assays) were also purchased from Qiagen: GAPDH (Catalog number QT00079247), ITPR1 (Catalog number
QT00056490), ITPR2 (Catalog number QT01336468), ITPR3 (Catalog number QT00011865), miR-34a (Catalog number MS00003318), NFATC4 (NFATC4_1: QT00013587; NFATC4_2: QT01873326), ORAI1 (Catalog number QT00202587), ORAI2 (Catalog number QT00215229), ORAI3 (Catalog number QT00231910), RNU48 (Catalog number MS00007511), STIM1 (Catalog number QT00083538), and STIM2 (Catalog number QT00023744).

\section{Western blot analysis of endogenous NFATC4, STIM1, and PPP3R1 protein expression in Jurkat and cells}

To obtain endogenous protein extracts from Jurkat cells, $2.5 \times 10^{5}$ cells/well were seeded out in six-well plates and were transfected either with ANC or with syn-hsamiR-34a-5p miScript miRNA Mimics (QIAGEN N.V., MIMAT0000255: 5'-UGGCAGUGUCUUAGCUGGUU GU-3'), complying with HiPerFect ${ }^{\text {tw }}$ transfection reagent protocol (Qiagen). Further analysis was performed after an incubation time of $48 \mathrm{~h}$. The transfected cells were lysed by $2 \times$ lysis buffer $(130 \mathrm{mM}$ Tris/HCl, $6 \%$ SDS, $10 \%$ 3-Mercapto-1,2-propanediol, 10\% glycerol) and sonification. Whole-cell protein extracts $(15 \mu \mathrm{g})$ were separated by SDS-PAGE on Mini-Protean TGX Stain-Free ${ }^{\mathrm{TM}}$ Precast Gels (Bio-Rad Laboratories Inc., Hercules, A, USA). Protein bands of NFATC4 and STIM1 were transfered by electroblotting to a nitrocellulose membrane (Whatman, GE Healthcare, Freiburg, Germany). For PPP3R1 analysis, protein bands were transferred to a polyvinylidene fluoride membrane. Protein bands were detected using specific monoclonal antibodies for STIM1 (anti-STIM1; Cat\# 5668 S) and NFATC4 (anti-NFAT3; Cat\# 2183 S) from Cell Signaling Technology, Inc. (Danvers, USA) and for PPP3R1 (Cat\# MA5-23933) from Thermo Fisher Scientific (Waltham, USA). $\beta$-Actin served as loading control and was detected by monoclonal antibeta-Actin antibody (Cat\# A5441) from Sigma Aldrich (Munich, Germany). Secondary antibodies were purchased from Sigma Aldrich.

\section{Quantification of IL-2 production by ELISA assay}

Jurkat E6.1 cells, $2.5 \times 10^{5}$ cells/well were seeded out in six-well plates and transfected with ANC or syn-hsa-miR34a-5p miScript miRNA Mimics (QIAGEN N.V.) as described for protein extraction. Twenty-four hours after transfection, cells were collected for activation. The transfected cells were transferred to a 48-well plate and seeded out to a count of $3.5 \times 10^{5}$ cells/well in a volume of $350 \mu \mathrm{l}$ fresh medium, supplemented with MACSiBead ${ }^{\mathrm{mi}}$ Particles (Bead:Cell ratio 1:2) from human $\mathrm{T}$ Cell Activation/ Expansion Kit (Miltenyi Biotec $\mathrm{GmbH}$ ) and $5 \mathrm{ng} / \mathrm{ml}$ of PMA (Sigma Aldrich) was added. Incubation time was additional $24 \mathrm{~h}$ before supernatants were collected and total cell count was estimated. IL-2 quantification was performed 
following the protocol of Human IL-2 DuoSet ${ }^{\circledR}$ ELISA of R\&D Systems, Inc. (Minneapolis, Minnesota, USA).

\section{Statistical evaluation and quantification}

Statistical evaluation was performed by Student's $t$-test, using SigmaPlot 10 software (Systat, Chicago, USA). A normal distribution of data was expected in all experiments. Densitometric analysis of western blot bands was performed, using Image Lab Software Version 5.2.1 (BioRad Laboratories, Inc.). The difference of data sets was considered to be significant at a $p$-value $\leq 0.05$. Asterisks in the figures correspond to the statistical significance: " $p \leq 0.05,{ }^{* * *} p<0.01,{ }^{* * * *} p<0.001$.

\section{Acknowledgements}

We thank Birgit Glombitza and Tanja Tänzer from Institute of Virology and Center of Human and Molecular Biology for their excellent technical support. This work was supported by the European Union's Seventh Framework Programme for Research, Technological Development and Demonstration [grant number: 600841], and by the Deutsche Forschungsgemeinschaft [FOR2289-P6, SFB894 A2]. Further, the work in this manuscript has been funded by the Michael J. Fox foundation. We appreciate the financial support of the European Union, the Deutsche Forschungsgemeinschaft, and the Michael J. Fox Foundation.

\begin{abstract}
Author details
${ }^{1}$ Institute of Human Genetics, Saarland University, 66421 Homburg, Germany. ${ }^{2}$ Molecular Biophysics, Center for Integrative Physiology and Molecular Medicine, School of Medicine, Saarland University, 66421 Homburg, Germany. ${ }^{3}$ Institute of Virology and Center of Human and Molecular Biology, Saarland University, 66421 Homburg, Germany. ${ }^{4}$ Institute of Virology and Center of Human and Molecular Biology, Medical School, Saarland University, 66421 Homburg, Germany. ${ }^{5}$ Chair for Clinical Bioinformatics, Saarland University, 66123 Saarbrücken, Germany. ${ }^{6}$ Center for Bioinformatics, Saarland Informatics Campus, Saarland University, 66123 Saarbrücken, Germany
\end{abstract}

\section{Conflict of interest}

The authors declare no competing financial interests.

\section{Publisher's note}

Springer Nature remains neutral with regard to jurisdictional claims in published maps and institutional affiliations.

Supplementary Information accompanies this paper at (https://doi.org/ 10.1038/s41419-018-1050-7).

Received: 5 June 2018 Revised: 10 September 2018 Accepted: 10 September 2018

Published online: 27 September 2018

\section{References}

1. Feske, S. Calcium signalling in lymphocyte activation and disease. Nat. Rev. Immunol. 7, 690-702 (2007).

2. Alderson, M. R. et al. Fas ligand mediates activation-induced cell death in human T lymphocytes. J. Exp. Med. 181, $71-77$ (1995).

3. Volpe, E., Sambucci, M., Battistini, L. \& Borsellino, G. Fas-Fas ligand: checkpoint of T cell functions in multiple sclerosis. Front. Immunol. 7, 382 (2016).

4. Harr, M. W. \& Distelhorst, C. W. Apoptosis and autophagy: decoding calcium signals that mediate life or death. Cold Spring Harb. Perspect. Biol. 2, a005579 (2010).

5. Imboden, J. B. \& Pattison, G. Regulation of inositol 1,4,5-trisphosphate kinase activity after stimulation of human T cell antigen receptor. J. Clin. Invest. 79, 1538-1541 (1987).
6. Imboden, J. B. \& Stobo, J. D. Transmembrane signalling by the T cell antigen receptor. Perturbation of the T3-antigen receptor complex generates inositol phosphates and releases calcium ions from intracellular stores. J. Exp. Med. $161,446-456$ (1985).

7. Jayaraman, T., Ondriasova, E., Ondrias, K., Harnick, D. J. \& Marks, A. R. The inositol 1,4,5-trisphosphate receptor is essential for T-cell receptor signaling. Proc. Natl Acad. Sci. USA 92, 6007-6011 (1995).

8. Baba, Y. et al. Coupling of STIM1 to store-operated Ca2 + entry through its constitutive and inducible movement in the endoplasmic reticulum. Proc. Nat Acad. Sci. USA 103, 16704-16709 (2006)

9. Putney, J. W. Jr. Capacitative calcium entry: sensing the calcium stores. J. Cell Biol. 169, 381-382 (2005).

10. Liou, J. et al. STIM is a Ca2 + sensor essential for $\mathrm{Ca} 2+$-store-depletiontriggered Ca2 + influx. Curr. Biol. 15, 1235-1241 (2005).

11. Vig, M. et al. CRACM1 is a plasma membrane protein essential for storeoperated Ca2 + entry. Science 312, 1220-1223 (2006).

12. Putney, J. W. Jr. New molecular players in capacitative Ca2 + entry. J. Cell Sci. 120, 1959-1965 (2007).

13. Cui, C., Merritt, R., Fu, L. \& Pan, Z. Targeting calcium signaling in cancer therapy Acta Pharm. Sin. B 7, 3-17 (2017).

14. Hogan, P. G., Lewis, R. S. \& Rao, A. Molecular basis of calcium signaling in Iymphocytes: STIM and ORAl. Annu. Rev. Immunol. 28, 491-533 (2010).

15. Clipstone, N. A. \& Crabtree, G. R. Identification of calcineurin as a key signalling enzyme in T-lymphocyte activation. Nature 357, 695-697 (1992).

16. Xie, J., Pan, H., Yao, J., Zhou, Y. \& Han, W. SOCE and cancer: Recent progress and new perspectives. Int. J. Cancer 138, 2067-2077 (2016).

17. Feske, S. ORAl1 and STIM1 deficiency in human and mice: roles of storeoperated $\mathrm{Ca} 2+$ entry in the immune system and beyond. Immunol. Rev. $\mathbf{2 3 1}$ 189-209 (2009).

18. Picard, C. et al. STIM1 mutation associated with a syndrome of immunodeficiency and autoimmunity. N. Engl. J. Med. 360, 1971-1980 (2009).

19. Zhang, $\mathrm{S}$. et al. Role of dicer enzyme in the regulation of store operated calcium entry (SOCE) in CD4 + T cells. Cell Physiol. Biochem. 39, 1360-1368 (2016).

20. Bartel, D. P. MicroRNAs: genomics, biogenesis, mechanism, and function. Cell 116, 281-297 (2004)

21. Grimson, A. et al. MicroRNA targeting specificity in mammals: determinants beyond seed pairing. Mol. Cell 27, 91-105 (2007).

22. Winter, J., Jung, S., Keller, S., Gregory, R. I. \& Diederichs, S. Many roads to maturity: microRNA biogenesis pathways and their regulation. Nat. Cell Biol. 11, 228-234 (2009).

23. Sonkoly, E., Stahle, M. \& Pivarcsi, A. MicroRNAs and immunity: novel players in the regulation of normal immune function and inflammation. Semin. Cancer Biol. 18, 131-140 (2008)

24. Garzon, R., Calin, G. A. \& Croce, C. M. MicroRNAs in cancer. Annu. Rev. Med. 60 167-179 (2009)

25. Misso, G. et al. Mir-34: a new weapon against cancer? Mol. Ther. Nucleic Acids $\mathbf{3}$ e194 (2014)

26. Chen, F. \& Hu, S. J. Effect of microRNA-34a in cell cycle, differentiation, and apoptosis: a review. J. Biochem. Mol. Toxicol. 26, 79-86 (2012).

27. Saito, Y., Nakaoka, T. \& Saito, H. microRNA-34a as a therapeutic agent against human cancer. J. Clin. Med 4, 1951-1959 (2015).

28. Beg, M. S. et al. Phase I study of MRX34, a liposomal miR-34a mimic, administered twice weekly in patients with advanced solid tumors. Invest. New Drugs 35, 180-188 (2017).

29. Slabakova, E., Culig, Z., Remsik, J. \& Soucek, K. Alternative mechanisms of miR34a regulation in cancer. Cell Death Dis. 8, e3100 (2017).

30. Hart, M. et al. Identification of miR-34a-target interactions by a combined network based and experimental approach. Oncotarget 7, 34288-34299 (2016).

31. Leidinger, P. et al. What makes a blood cell based miRNA expression pattern disease specific?--a miRNome analysis of blood cell subsets in lung cancer patients and healthy controls. Oncotarget 5, 9484-9497 (2014).

32. Pfeifhofer-Obermair, C., Thuille, N. \& Baier, G. Involvement of distinct PKC gene products in T cell functions. Front. Immunol. 3, 220 (2012).

33. Niemeyer, B. A. Changing calcium: CRAC channel (STIM and Orai) expression splicing, and posttranslational modifiers. Am. J. Physiol. Cell Physiol. $\mathbf{3 1 0}$ C701-C709 (2016)

34. Nagaleekar, V. K. et al. IP3 receptor-mediated Ca2 + release in naive CD4 T cells dictates their cytokine program. J. Immunol. 181, 8315-8322 (2008). 
35. Sugiyama, T. et al. Subtypes of inositol 1,4,5-trisphosphate receptor in human hematopoietic cell lines: dynamic aspects of their cell-type specific expression. FEBS Lett. 349, 191-196 (1994).

36. Miyakawa, T. et al. Encoding of Ca2 + signals by differential expression of IP3 receptor subtypes. EMBO J. 18, 1303-1308 (1999).

37. Holloway, M. P. \& Bram, R. J. Co-localization of calcium-modulating cyclophilin ligand with intracellular calcium pools. J. Biol. Chem. 273, 16346-16350 (1998).

38. Bram, R. J. \& Crabtree, G. R. Calcium signalling in T cells stimulated by a cyclophilin B-binding protein. Nature 371, 355-358 (1994).

39. Chan, S. L. et al. Calcium-modulating cyclophilin ligand is essential for the survival of activated T cells and for adaptive immunity. J. Immunol. 195, 5648-5656 (2015).

40. Cai, X. Molecular evolution and structural analysis of the $\mathrm{Ca}(2+)$ releaseactivated $\mathrm{Ca}(2+)$ channel subunit, Orai. J. Mol. Biol. 368, 1284-1291 (2007).

41. Feske, S. et al. A mutation in Orai1 causes immune deficiency by abrogating CRAC channel function. Nature 441, 179-185 (2006).

42. Hoth, M. \& Niemeyer, B. A. The neglected CRAC proteins: Orai2, Orai3, and STIM2. Curr. Top. Membr. 71, 237-271 (2013).

43. Oh-Hora, M. et al. Dual functions for the endoplasmic reticulum calcium sensors STIM1 and STIM2 in T cell activation and tolerance. Nat. Immunol. 9, 432-443 (2008).

44. Schindl, R. et al. Plasticity in Ca2 + selectivity of Orai1/Orai3 heteromeric channel. Proc. Natl Acad. Sci. USA 106, 19623-19628 (2009).

45. Alansary, D., Bogeski, I. \& Niemeyer, B. A. Facilitation of Orai3 targeting and store-operated function by Orai1. Biochim Biophys. Acta 1853, 1541-1550 (2015).

46. Bogeski, I. et al. Differential redox regulation of ORAl ion channels: a mechanism to tune cellular calcium signaling. Sci. Signal 3, ra24 (2010).

47. Szlufcik, K., Missiaen, L., Parys, J. B., Callewaert, G. \& De Smedt, H. Uncoupled IP3 receptor can function as a $\mathrm{Ca} 2+-$ leak channel: cell biological and pathological consequences. Biol. Cell 98, 1-14 (2006).

48. Roos, J. et al. STIM1, an essential and conserved component of store-operated Ca2 + channel function. J. Cell Biol. 169, 435-445 (2005).

49. Yuan, H. Y. et al. MicroRNA-34a targets regulator of calcineurin 1 to modulate endothelial inflammation after fetal cardiac bypass in goat placenta. Placenta 51, 49-56 (2017).

50. Kim, S. S., Lee, E. H., Lee, K., Jo, S. H. \& Seo, S. R. PKA regulates calcineurin function through the phosphorylation of RCAN1: identification of a novel phosphorylation site. Biochem. Biophys. Res. Commun. 459, 604-609 (2015).

51. Rusnak, F. \& Mertz, P. Calcineurin: form and function. Physiol. Rev. 80, 1483-1521 (2000)

52. Klee, C. B., Ren, H. \& Wang, X. Regulation of the calmodulin-stimulated protein phosphatase, calcineurin. J. Biol. Chem. 273, 13367-13370 (1998).

53. Yang, S. A. \& Klee, C. B. Low affinity Ca2 +-binding sites of calcineurin B mediate conformational changes in calcineurin A. Biochemistry 39, 16147-16154 (2000).

54. Rao, A., Luo, C. \& Hogan, P. G. Transcription factors of the NFAT family: regulation and function. Annu. Rev. Immunol. 15, 707-747 (1997).

55. Gwack, Y., Feske, S., Srikanth, S., Hogan, P. G. \& Rao, A. Signalling to transcription: store-operated Ca2 + entry and NFAT activation in lymphocytes. Cell Calcium 42, 145-156 (2007).

56. Serfling, E. et al. The role of NF-AT transcription factors in T cell activation and differentiation. Biochim. Biophys. Acta 1498, 1-18 (2000).

57. Cheng, J., Tang, W., Su, Z. \& Wei, Q. Mutation of calcineurin subunit B M118 influences the activities of NF-AT and p53, but not calcineurin expression level. Biochem. Biophys. Res. Commun. 413, 481-486 (2011).
58. Srikanth, S. \& Gwack, Y. Orai1-NFAT signalling pathway triggered by T cell receptor stimulation. Mol. Cells 35, 182-194 (2013).

59. Hoey, T., Sun, Y. L., Williamson, K. \& Xu, X. Isolation of two new members of the NF-AT gene family and functional characterization of the NF-AT proteins. Immunity 2, 461-472 (1995).

60. Lyakh, L., Ghosh, P. \& Rice, N. R. Expression of NFAT-family proteins in normal human T cells. Mol. Cell Biol. 17, 2475-2484 (1997).

61. Macian, F. NFAT proteins: key regulators of T-cell development and function. Nat. Rev. Immunol. 5, 472-484 (2005).

62. Kojima, $H$. et al. Expression of nuclear factor of activated $T$ cells mRNA in maternal peripheral blood cells. Am. J. Reprod. Immunol. 49, 139-148 (2003).

63. Kaminuma, O. et al. Downregulation of NFAT3 due to lack of T-Box transcription factor TBX5 is crucial for cytokine expression in T cells. J. Immunol. 200, 92-100 (2018).

64. Boyman, O., Kolios, A. G. \& Raeber, M. E. Modulation of T cell responses by IL-2 and IL-2 complexes. Clin. Exp. Rheumatol. 33, S54-S57 (2015).

65. Cantrell, D. A. \& Smith, K. A. The interleukin-2 T-cell system: a new cell growth model. Science 224, 1312-1316 (1984).

66. Sim, G. C. \& Radvanyi, L. The IL-2 cytokine family in cancer immunotherapy. Cytokine Growth Factor Rev. 25, 377-390 (2014).

67. Chen, D. \& Rothenberg, E. V. Interleukin 2 transcription factors as molecular targets of CAMP inhibition: delayed inhibition kinetics and combinatorial transcription roles. J. Exp. Med 179, 931-942 (1994).

68. Tanwar, J. \& Motiani, R. K. Role of SOCE architects STIM and Orai proteins in cell death. Cell Calcium 69, 19-27 https://doi.org/10.1016/j.ceca.2017.06.002 (2017).

69. Parekh, A. B. \& Putney, J. W. Jr. Store-operated calcium channels. Physiol. Rev. 85, 757-810 (2005)

70. Vervliet, $\mathrm{T}$. et al. Modulation of $\mathrm{Ca} 2+$ signaling by anti-apoptotic B-cell lymphoma 2 proteins at the endoplasmic reticulum-mitochondrial interface. Front. Oncol. 7, 75 (2017).

71. De Panfilis, G. et al. Identification of Fas-L-expressing apoptotic T lymphocytes in normal human peripheral blood: in vivo suicide. Am. J. Pathol. 158, 387-391 (2001).

72. Strasser, A., Jost, P. J. \& Nagata, S. The many roles of FAS receptor signaling in the immune system. Immunity 30, 180-192 (2009).

73. Holtz-Heppelmann, C. J., Algeciras, A., Badley, A. D. \& Paya, C. V. Transcriptional regulation of the human FasL promoter-enhancer region. J. Biol. Chem. 273 4416-4423 (1998)

74. Nakano, K., Saito, K., Mine, S., Matsushita, S. \& Tanaka, Y. Engagement of CD44 up-regulates Fas ligand expression on $T$ cells leading to activation-induced cell death. Apoptosis 12, 45-54 (2007).

75. Kauppinen, A., Suuronen, T., Ojala, J., Kaarniranta, K. \& Salminen, A. Antagonistic crosstalk between NF-kappaB and SIRT1 in the regulation of inflammation and metabolic disorders. Cell Signal 25, 1939-1948 (2013).

76. Yamakuchi, M. \& Lowenstein, C. J. MiR-34, SIRT1 and p53: the feedback loop. Cell Cycle 8, 712-715 (2009).

77. Grynkiewicz, G., Poenie, M. \& Tsien, R. Y. A new generation of Ca2 + indicators with greatly improved fluorescence properties. J. Biol. Chem. 260, 3440-3450 (1985).

78. Dweep, H. \& Gretz, N. miRWalk2.0: a comprehensive atlas of microRNA-target interactions. Nat. Methods 12, 697 (2015).

79. Beitzinger, M., Peters, L., Zhu, J. Y., Kremmer, E. \& Meister, G. Identification of human microRNA targets from isolated argonaute protein complexes. RNA Biol. 4, 76-84 (2007)

80. Ho, S. N., Hunt, H. D., Horton, R. M., Pullen, J. K. \& Pease, L. R. Site-directed mutagenesis by overlap extension using the polymerase chain reaction. Gene 77, 51-59 (1989). 